\title{
The Politics of Identity and Regional Integration - Updating Global Perspectives
}

\author{
Manuel Montoya and Lucio Lanucara
}

University of New Mexico

\begin{abstract}
Regional integration (RI) is an essential part of the discourse on the global economy, viewed often as a "stumbling block" or "building block." However, little research exists that connects RI in the context of a politics of identity (PoI), which can be used to describe the evolving tensions between national sentiment and regional economic cooperation. This paper performs a Web of Science and Google Scholar review of 136 articles to determine how RI is discussed in the context of PoI. Our review demonstrated that the conceptual frameworks normally used to think about PoI are underexpressed in the context of RI. We discuss why this is the case and identify themes to illustrate the connection. We then suggest conceptual frameworks to enhance the discussion of PoI as it relates to RI, particularly as it relates to the teaching of RI across learning groups.
\end{abstract}

\section{Keywords}

egional integration; Politics of Identity; international management; cultural economy; nationalism

\section{Introduction}

Several phenomena have prompted the need to understand regional integration (RI) in an identity-based context. This includes not only the policies of populist leaders such as Donald Trump or Boris Johnson, but also specific surprising effects-for instance, the discussion on Brexit reigniting the tensions along the border between Northern Ireland and Ireland. Issues of RI are characterized by challenges to supranational governance grounded largely in the politics of identity (PoI) because of a prominent view of multilateral institutions: that they are unaccountable, unelected institutions that do not reflect the popular sovereignty associated with democratic institutions (Keohane 2003). Popular sovereignty is an important aspect of PoI, an element of nationalism that itself has subcategories of identity that are difficult to represent. Without proper framing, how is one to navigate the

\footnotetext{
* Manuel Montoya (corresponding author), MSC 05 3090, University of New Mexico Albuquerque, NM, 87105, United States; mrmonto@unm.edu; Lucio Lanucara, MSC 05 3090, University of New Mexico, Albuquerque, NM 87105, United States; llanucara@unm.edu.
} 
relationship between identity, community, and the more technical aspects of economic cooperation? For example, how did the UK leaving the European Union (EU) contribute to the Irish being reminded of deep tensions between Catholic and Protestants or about Welsh fishermen who believe that German immigration policies are destroying their livelihoods? How can one view the withdrawal from a common market as a referendum on immigration policies or how and why do ethnic minorities become a scapegoat for stifled economic growth? These issues replicate themselves across the world, and while they become criticisms of RI in superficiem, we rarely see a nuanced discussion of the PoI that inform these tensions. Moreover, the different forms of RI are treated uniformly, even though each form (e.g., a trade agreement versus a common market) has a very different relationship with how the PoI are introduced. This has prompted us to ask the following questions:

1. What themes prompt a PoI to intersect with RI?

2. How do various forms of RI produce different entry points for the PoI?

3. What frameworks can be used to analyze the PoI in an RI context? This paper reviews themes, forms, and frameworks that respond to these questions, while simultaneously constructing a more nuanced analytic framework whereby RI is evaluated in a PoI context. It was our intention to first determine if an initial review of the technical terms used to describe RI would connect to the more hermeneutic frameworks used to teach identity. We correctly hypothesized that the literature on RI was somewhat disconnected from contributions to the discourse on identity formation, an issue we try to address in this paper.

It is important to note that this search originated from our interest as educators who teach general issues of international business, international relations, and global political economy to university students. It has been our experience that the subject of RI operates out of a very technical understanding of those terms. On the other hand, the concept of identity is a very versatile concept, which we have found resonates with students for obvious reasonsfirst, because these are individuals who are deeply exploring who they are and what they will become, but second, because they are wrestling with the same issues everyone is facing during these complex and fast-changing times. This prompted us to reflect on how we can effectively teach the connection between identity, the PoI and the issues of economic cooperation that largely fit within the "subject matter" of RI. We wanted to explore how "textbook" information (which is derived from technical discussions among experts who treat economic issues) connects to people who receive this information more 
viscerally as it relates to who they are and how their practices and traditions are impacted by these discussions. Hence, our review is one motivated by pedagogical interests rather than by comprehensively capturing the state of the academic discussion.

\section{Section 1: Methodology}

\section{A. Terminology}

The "PoI" refers to the body of knowledge that studies the construction of human identity as it relates to a general political economy. This includes traditional categories of identity (race, class, gender, creed, and sexuality) but also incorporates ways the constantly evolving way that people represent belonging to communities and how those tensions manifest as a body politic (Keith and Pile 2004). This differs slightly from the vernacular usage of "identity politics," which now often refers to political ideologies defined within polemical politics (e.g., criticisms of people using "identity politics" in their agenda). In most cases, these terms are conflated in the literature, but given recent usage of the term, we rely on the more standard academic phrasing that emphasizes a politics "of" identity rather than presuming that identity is an immutable object within the theater of political discourse. More importantly, we were less interested in making the distinction between the two, but rather wished to understand how various forms of identity are evoked when discussing ways that economic cooperation evolves. Given how easily terms such as "identity" and "economic cooperation" could appear in the same discussion, we allowed "identity" to appear with a broader range of distinction and turned our attention to the more technical terms that could be used to describe RI or economic cooperation. We did this to see whether (and how) "identity" appears as a thematic concept in literature that employed the technical economic vocabulary of regional integration. Identity is a broad concept and one that captures the attention of people in different ways. Among the many ways identity is discussed, our definition leans heavily on the way that identity is discussed as a problem of cultural economy-how people imagine themselves to belong to political institutions and how identity forms across changing social and cultural landscapes (Anderson 2006).

"RI" may be broadly defined as any relationship between two or more countries that coordinates economic or political behavior. It can take several forms and levels of intensity. Thus, to distinguish each form of RI, we defined them as follows: 
A. Free Trade Agreement: a pact between two or more nations to reduce barriers to imports and exports among them;

B. customs union: a type of trade bloc between two or more nations that is composed of a free trade area with a common external tariff;

C. common market: a form of RI composed of the free movement of goods, services, and people within a given international area;

D. economic union: a form of RI wherein member nations incorporate a customs union and a common market, with additional shared economic policies;

E. monetary union: an economic union that also contains a shared and commonly used currency;

F. political union (supranationalism): a form of integration that includes an economic union but also contains shared social policies, traditionally unified by a constitution or other formal agreements.

Based on these definitions, treaties and other political compacts and their corresponding organizations did not necessarily qualify as a form of RI. For example, while NATO is an important political body that does organize political and economic choices, it was not included as a "political union."

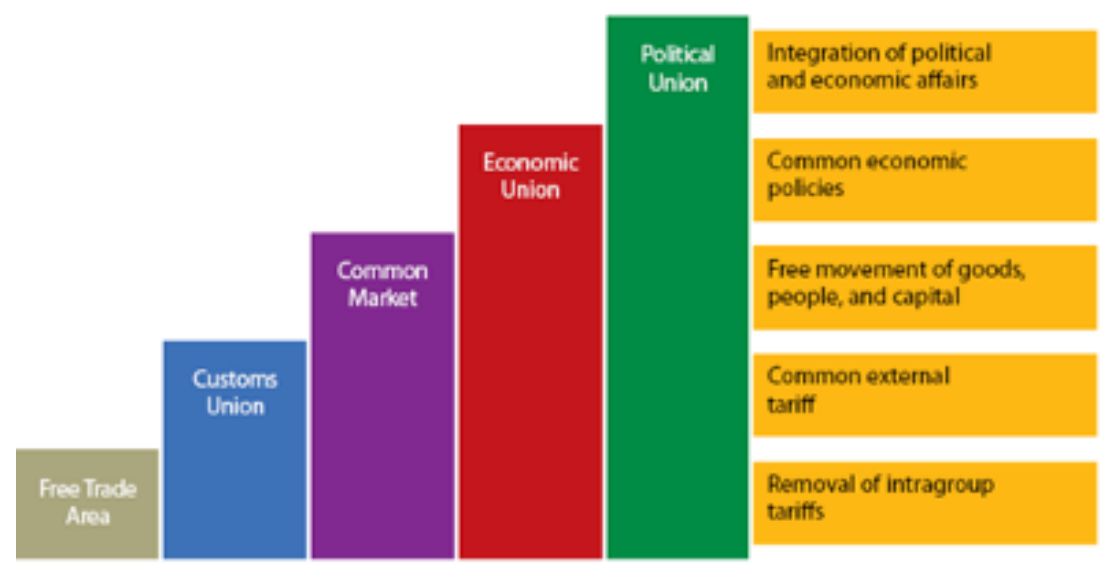

Fig. 1: Forms of Regional Integration (Peng 2005)

\section{B. Search Criteria}

For the survey component of this paper, we conducted a combination of a search of the Web of Science and Google Scholar databases peer-reviewed journal articles and book chapters that searched for keywords that related 
to RI and combined them with a search for the term PoI. We searched for academic materials starting in the year 1993. Because much of the literature available focuses on the EU, we selected the Treaty of Maastricht as the point of reference for any writing on RI that followed the formation of the European Community and its influence on the resulting global discourse. The following table represents the outcome of that search:

Tab. 1: Search Results for RI and PoI

\begin{tabular}{|l|l|}
\hline Search Type ("x" + PoI) & No. of articles selected using keyword filters \\
\hline Regional Integration & 69 \\
\hline Free Trade Agreement & 13 \\
\hline Customs Union & 3 \\
\hline Common Market & 8 \\
\hline Economic Union & 10 \\
\hline Monetary Union & 12 \\
\hline Political Union & 9 \\
\hline Supranationalism & 13 \\
\hline Total Results found & 136 \\
\hline Sum of the Times Cited & 748 \\
\hline Average Citations per Item & 5.5 \\
\hline h-index (Web of Science) & 3.1 \\
\hline
\end{tabular}

Appendix A contains a full account of the search results, including specific citation information for each journal and how they were coded in the review process. The next section summarizes how the reviewed literature discussed RI in a PoI context.

\section{Section 2. Forms of RI and Pol}

Generally, we observed that RI is not a term that is used directly in a great deal of the literature we explored. Instead, the more specific forms of RI 
described in Section 1 are utilized. For the purposes of this section, what we are interested in is providing an account of the interaction with PoI emerging from our review of existing scholarly production. Each subsection refers specifically to the literature as it describes a specific form of RI and its connection to PoI.

\section{A. Free Trade Agreements}

This kind of integration does not interfere with identity and sovereignty, as each country remains free to adopt its own trade policies with other countries and, while goods and services might be allowed to flow with limited or no restrictions, workers do not typically have any facilitation in emigration between countries. The North American Free Trade Agreement (NAFTA) is a good example of this. Galvez (2018) establishes a useful ethnography of the way that free trade agreements impact foodways, which in turn have a dramatic effect on personal identity. This book represents many of the thoughts presented in the literature specific to free trade agreements. It is not surprising, therefore, that much of the discussion regarding PoI and free trade agreements is focused on two major themes: the goods traded across borders and their symbolic significance, and the labor associated with producing those goods. Galperin suggests that in the early years of the EU and the burgeoning discussion on Mercosur that all objects traded across borders are cultural objects, and thus, have a symbolic meaning that has political implications. In each of these discussions, the "free" part of free trade represented a liberalization of the cultural barriers that were significant to identity (Galperin 1999, Gouvea and Montoya, 2014). In this sense, much of what free trade is about is the negotiation of what objects become part of the cultural economy, which reinforces the concept of free trade as a vehicle for neoliberalism. This itself produces larger questions about why and how objects create the sentimentality and nostalgia that activates nationalistic sentiments. In most of the literature observed, free trade agreements serve as a proxy for economic cooperation. For example, Dorn et al. (2016) suggest that polarized politics have used free trade as the shorthand for all aspects of economic cooperation because it is a widely popular and accessible term. Piccolino (2020) further emphasizes the role of populism in debates over the influence on trade on the welfare of the population. In most cases, the liberalization of cross-border trade activates a sentiment among the general population because the softening of borders is the most symbolic theme for change for most people (DeSoucey, 2010; Galvez, 2018). 


\section{B. Customs Unions}

While the literature recognizes that a customs union requires its member states to give up part of their sovereign freedom by agreeing to adopt common external policies, this level of integration also has a limited impact on identity issues. One of the most significant processes has to do with denomination of origin, and specifically the liabilities of foreignness associated with these denominations (Onis 1999). Country of origin labeling and the taxonomies required to calculate tariffs are a significant part of the PoI. Surprisingly, the literature does not readily make this connection. Even though customs issues are significant to the discussion of economic impact, there are not many steps taken in the literature to directly connect the way that traded objects are classified (and later taxed or regulated) to the way that people formulate an identity. For example, while entities like Benelux have a relevant level of cultural and social closeness, the EU had maintained for a long time a customs union with Turkey, a country with very profound cultural and religious differences with the European bloc, even in the more tense relationships developed in the past few years, as the country seems to develop in a more illiberal and potentially theocratic regime (Mansfield and Milner 2012). Customs unions are by far the most technical form of RI we explored in the literature and rarely appears in relation to a concept of identity unless bundled into discussions that have more symbolic significance to a wide audience. This further supports our assumption that when more technical economic terms are introduced, the literature disconnects from the cultural and social dimensions of identity. It is noteworthy that there are several examples of customs issues that have a very indirect influence on how groups of people discuss a sense of threat or a loss of identity. For example, recent studies of customs unions in Canada (Cote-Boucher, 2013) describe the "micro-politics" of customs at the Canadian border to explore how border officials have evolved from processing commodities into a security force.

\section{C. Common Markets}

While not affecting fundamental issues such as taxation and spending policies, or monetary policy and political decisions, the freedom of movement of persons between member states requires compatible economies and cultures to avoid major pushbacks from the local population, who might feel threatened by a disruption of their economic and sociocultural surroundings. The literature suggests that the majority of discussions surrounding common markets focuses on two themes: migration and transnational identity. In the case of migration, the discussion about changing demographics becomes the 
key factor. For example, Rwengabo describes the development of the East African common market as the transition of a mobile labor market to habits and political choices that then create a form of transnational citizenship. It is in this transition from laborer to citizen that an "additional but notnecessarily competing social contract" develops over time within common markets (Rwengabo 2015).

Thus, common markets transition from being largely transactional to a question of regional and national emotional sentiments. In the EU, for instance, the Common Market was completed in the late 1980s, subsequent to the Single European Act, at a time during which the appreciation of European people for the institutions created after World War II was still extremely high, based on the double psychological positive effect of the regained peace after World War II and the sense of necessary unity during the Cold War. However, notwithstanding a strengthened internationalism in the years immediately after the end of the Cold War, which represented the limit of emotional acceptance for many segments of European population, after which the view of the EU construction started changing rapidly toward a more critical perception (Gerrits 2016). These two examples in the literature represent how the emotional connection to people and the way they are affected by change steers toward a more demographic focus, where people are replaced by "populations." Wajner and Roniger (019) describe how the discussion of free moving populations then turns into a question about how changing demographics then ignite sentiments of a loss of identity. As economic cooperation turns toward the free movement of people among those who cooperate, the physicality of people moving across borders serves as highly political linchpin. We observed, however, that there is a disconnect between migration patterns that are seen as threatening (the "illegal alien") and those patterns forged out of an evolution of economic cooperation. Rarely does the idea of a common market ignite a sentiment about resources becoming scarcer because of people freely moving across borders. In fact, Kurtis and Kopytowska (2014) submit that common markets produce a sense of equity among places that more often suggests that "one can return home" in a common market because the participants in a common market see each other's spaces as having more equality and hence having less propensity for the movement of people to happen more by choice than by force or conditions of great disparity. For this reason, common markets have a very different relationship to a PoI perspective given the relatively egalitarian conditions wherein that term operates. 


\section{D. Economic and Monetary Unions}

The literature suggests that this is the point where the discussion of identity aligns with the concept of citizenship. The most recent scholarship finds that economic policies become "artificial," meaning the documents and policies constructed here become "heritage objects" (Lähdesmäki and Mäkinen 2019). Regulations become a part of daily discourse and thus compete with other questions or debates of the time, which in turn become a point of reference for how people define themselves both as citizens and as human subjects (Mycock 2012). The elevated status of economic policies further highlights the importance of those processes to a larger number of people. Hence, it becomes popularized as a space where the stakes of one's identity are claimed. This was demonstrated by the then-new resistance to the ratification of the Maastricht agreements, represented in referenda held at the time in France, the Netherlands, and Denmark. While most people "felt European" to some extent, the Maastricht Treaty made that question a more integrated part of the reality of European citizenship. No longer an abstract fantasy, forms of economic union become the turning point for larger questions of nationalism and cultural economy.

Monetary unions include the added dimension of having a specific and meticulously composed symbolism embedded in the circulation of a common currency. This has been long understood, particularly among philosophers and cultural critics. Georg Simmel famously noted that money is a "highly signified form of language" and that money takes on one of the most significant cultural forms from which citizenry is derived (Simmel 2004). Again, the question of identity transitions to a concept of citizenship and in the case of money, heritage. As mentioned above, the institution of the euro with the Maastricht Treaty has led in fact to the first moment of resistance against further integration, with French people only narrowly passing it in a referendum and the Danish people initially refusing it. Since then, however, the euro has become a fundamental feature of European life, with some warning about the reciprocal relationship between money and identity. To this point, several authors suggest that money has an added function, as a symbol of sovereignty, which produces tensions about a common identity each time a new currency or new symbolism is introduced (Coparoso and Keeler, 1993; Kaelberer 2004).

Since the Maastricht Treaty crisis, tensions about national identity grew in many EU member states, their roots being linked to economic crisis, pushback against perceived identity threats (such as the monetary union and the failed proposal for a European constitution), and immigration (Gerrits 
2016), eventually leading to the growth of nationalist populist movements in most of the leading countries. The literature suggests that the perceived importance of economic policies and the development and maintenance of money connect the PoI to the importance of citizenship and heritage, which combined becomes a fundamental root of modern nationalism.

\section{E. Political Unions and Supranationalism}

The literature suggests that, as a form of policy, coordinated efforts to achieve a political union tell us much about the contested bodies (goods, services, people, and embodied ideas) that are shaped by the processes of regional economic integration. Scholars of regional financial policies suggest that economic policies are often predicated upon the fantasy of a political union (Bhalla, 2016; Jones 2019). Much like Alexander Hamilton argued for a common currency to create a common identity to wage against a common enemy, economic policies are often about responsiveness to a perceived external threat that contains a market force. It is notable that at this level, there is a conflation of the terms "market" with "citizen," which at this junction crystallizes as a hard boundary, wherein a distinction between a market and a citizen is not made as much as it would in a free trade agreement. In short, markets have no PoI until they are contained by the state.

This leads to an interesting discussion on supranationalism. Once political unions are seen as static (the "state" in nation-state), the political and cultural economy that produces the PoI becomes much more complex. This explains why the concept of nationalism is such a common expression of the PoI.

As the 2008 economic crisis revealed, multilateral institutions have largely focused on processes and outcomes for addressing global problems. This was particularly evident in the treatment of the sovereign debt crisis in Greece. Already in 2010, various authors were noticing that the management of the crisis was reducing the credibility of the EU both as an intergovernmental organization and as a more integrated area (Zahariadis 2010), while more recent studies have highlighted how the Greek crisis and the subsequent adoption of the Stability and Growth Pact has greatly impacted the political dimension and voters' positions on financial issues in Europe, which tend now to be defined in terms of respect of the criteria or opposition to the monetary union (Katsanidou and Otjes 2016). However, as economic disenfranchisement, public health, and national security matters become manifest, it becomes clearer that these institutions have not focused on "detailed considerations of agency" that are, at their core, the most comprehensible parts of what makes a civil society function (Kahler 2013; Scholte 2004). 
Thus, economic nationalism is described in the literature as an escape from the perceived failures of multilateral governance. More particularistic forms of governance move away from larger cooperative institutions (e.g., a nation from a regional economic union, or a group of nations from a global economic forum) as an expression of agency within civil society. Terms such as "popular sovereignty," "self-determination," and "agency" are used as motivations to withdraw a part of one's stakes from multilateral processes. However, as Helleiner and Picker (2005) suggest in their edited volume Economic Nationalism in a Globalizing World, we cannot merely assume that economic nationalism necessarily translates into a form of protectionism.

Overall, it was notable that the literature itself proved that market driven, commercial, and often technical aspects of RI tend to move very quickly to questions of citizenship and heritage. In the following section, we will discuss themes that emerge from our review. Given the massive changes taking place globally, specifically renewed racial and ethnic tension amidst a global pandemic, we believe this section to be a valuable way to move the discussion forward.

\section{Section 3. Relevant Themes}

$\mathrm{RI}$ and the PoI intersect in the current literature not only through analysis of the different levels of RI, but also through analysis of certain fundamental themes, which we are going to examine in this section. It is noteworthy to consider that, while, as examined in the previous section, the relation between $\mathrm{RI}$ and the PoI is somewhat explored, other themes need to be examined for their connection with issues of the PoI.

\section{A. Nationalism and Nation-State}

Much has already been written about the nation-state as a political concept. Several studies of nationalism have noted that nationalism is a term conflated as a universal concept when in fact there are many varieties of nationalism. Nationalism is difficult to define: It can be considered an idea, idiom, belief, or ideology. Within this complexity, the political dimension of nationalism seems to be the most important one: nationalism is a way to operate, highlighting how to identify issues, although often empty as an ideological signifier (Gerrits 2016).

The most commonly known classification of the concept of nationalism distinguishes between ethnic nationalism and civic nationalism. This definition was first utilized by Hans Kohn in The Idea of Nationalism in 1945 and has been more recently embraced by Michael Ignatieff, who notes how 
these two types of nationalism determine the credibility of institutions meant to contain several sovereign powers (Ignatieff, 1994). Ethnic nationalism is based on blood and ethnicity, while civic nationalism is based on rules and civic cohesion. A variation along this classification is the distinction between nationalism and patriotism, or rather populist nationalism and patriotic nationalism. Although the modern concept of nation-state first emerged with the peace of Westphalia of 1648, it was during the twentieth century that distinctions were made between "good" nationalism and "bad" nationalism (Greenfeld 2018).

More recently, nationalism has been linked not only to historical processes that developed in a specific country, but also to a psychological process that elevates the importance of the nation-state as the "institution of choice" to mediate collective values and beliefs (Spruyt 1994). Pioneers in the field of cultural geography would use the idea that we select social structures to meet practical needs, and later, would rationalize those choices as having been produced from some organized narrative about collective destiny and sentiment, what Raymond Williams (1977) would refer to as a "structure of feeling." It is this conflation that ultimately becomes problematic: if nationalism is converted into a discourse on sentiment and nostalgia for a shared past, then it is predisposed to think about itself as a problem entirely about the PoI (Reus-Smit 1999; Gubrium and Holstein 2001).

As mentioned, RI appears more as a technical process, one about trade regulations and infrastructure, than it is about the historical consciousness of a people. Nationalism, on the other hand, contains and determines the sentiments of a people, has designated mythmaking properties. Nations are capable of discrediting regional systems by turning largely technical discussions into sentimental discussions. It is the resulting tension that makes nationalism such an important factor in understanding how the PoI manifests in RI.

\section{B. Development: Global North versus Global South}

As global phenomena such as COVID-19 and climate change continue to shape national agendas, the need for transnational agreements is clear. What is not clear, however, is how those agreements will include more stakeholders, particularly across socioeconomic barriers. It has been widely established within the literature on development that economic agendas form vis-a-vis "zones of proximity". In other words, organizations that set economic agendas such as G8 or OECD nations happen as a result of shared values and not necessarily in relation to achieving shared objectives (Payne 2008; Carranza, 
2017). This has led to more attention paid to concerns that "developing" nations are often left out or marginalized from key economic discussions (and decisions) based purely on how they are perceived as foreign or institutionally distant from those who have traditionally demonstrated progress. These concerns have led to a growing body of literature criticizing the use of binaries such as "First World/Third World," "Developed World/Developing World," and "Global North/Global South." Effectively, these categories become regional designations unto themselves, separating out groups of people based on economic indicators that imply other social renderings. Following the collapse of the Soviet Union, the communist/capitalist dichotomy that encapsulated a large part of global relations shifted to another set of categories. As great power politics based on military strength and Cold War ideology diminished, attention shifted to issues of development, poverty, and inequality. Several scholars suggest that great power conflict then became a discussion about ethnic conflict, and the word "ethnic" became a placeholder for those groups of people who were a) neither dominant in setting the global international agenda, and b) seen as fragile or failing states (Bowen 1996). In his seminal article on nation, race, and ethnicity, Connor (1978) suggested that ethnic states are places that have not passed an unspoken legitimacy test and therefore occupy a general field of belonging that we term "Third World." Consequently, states that do not meet a set of criteria imposed upon them during the Cold War, an era of power building that encouraged the development of sophisticated atomic weaponry and rewarded that development with voting power in international institutions (i.e., the UN Security Council), were informally designated as "ethnic" communities, nations in the sentimental/heritage sense, but with "undeveloped" capacity to participate in the prescribed world order. Scholarship in the fields of anthropology and international education have expressed this as a problem of hegemony, similar to "whiteness." Those who are developed/First/North participate in the world order without having to present themselves as having an ethnic background (Loftsdóttir 2009). It is only when one is deemed vulnerable, or when a state has failed, that institutions rely on ethnic designations (Menon, 2007; Katsanidou and Otjes, 2016).

Consider how nationalistic resentment of RI corresponds with white nationalism. The binary discourse on development contains a specific form of the PoI, one that presents ethnic groups as always vulnerable to the global agenda. As members of the "First World' encounter the result of a global development agenda, this has manifested as a form of "white grievance," which largely conveys guilt to structures that have facilitated global development 
(Thomas 2003). As discussions of regional integration continue, the question posed by these developmental binaries will become an increasingly active part of that discussion.

\section{C. Global Phenomena}

The concept of "identity" can easily become an overly complicated concept, especially when one introduces the way that globalization planetary-scale issues influence our lives. As we reviewed the literature, several key topics became increasingly salient, either because they were presented clearly in connection to our questions, or because they were absent. The themes described in the previous section are supplemented by the analysis of a number of global phenomena, as described in this section. We believe these themes serve as a way to refine and bridge the connections between a PoI and RI-themes that are seemingly apparent but not readily connected in initial discussions between the two.

\section{Digital Identity}

In 2014, the nations of Estonia, Israel, The Republic of Korea, New Zealand, and the United Kingdom convened to form an agreement for the development of a "coalition of Digital Nations and their corresponding economic agendas." Later named the "D5," these nations have coordinated efforts to share economic policies and in some cases, trade and regulatory practices consistent with conventional forms of RI, but only in relation to their capacity for digital growth. Since then, that organization has grown into the D9, and has created economic incentive policies such as free and available access to broadband to all citizens within these nations. In addition to the growing influence of digital access to identity, these nations are demonstrating a very clear connection between digital identity and RI in a manner that will require further reflection, particularly given how the different dynamics for how identity is presented, both in terms of economic processes but also on cultural norms and values, dramatically change when digital connectivity is introduced into daily life (Kobrin, 1995; Kar et al. 2019).

\section{Climate and Environment}

Climate change will unapologetically continue to intervene in matters of economic resilience and, by extension, to RI. Most recently, the potential collapse of the Three Gorges Dam has produced a discussion about the viability of global supply chains and the impact of slow and unanticipated climate effects on commercial connectivity. For this and many other reasons, climate 
change and other environmental factors will continue to play a significant role in how economic agendas are produced (Robinson and Herbert 2001). Beyond the UNFCCC Paris Agreement and the UN Sustainable Development Goals adopted in 2015, people will have to determine how environmental factors translate into the political will needed to address these problems. Hence, questions of identity and, by extension, about values will become a part of how forms of RI play into the context of issues such as climate change.

\section{Rural/Urban Divide and Interface}

According to a recent United Nations report on rural development, urbanization across planet Earth has increased by $57 \%$ since 2007 (UNCTAD 2017). As more people find economic security in urban regions, and as larger multinationals assert influence over agricultural landscapes, the divide between rural and urban will become increasingly problematic in terms of political inclusiveness and cohesion (Garcia 2005). In many countries, most people account for the increased divide between rural and urban populations for the rise of nationalistic sentiments and feelings of economic inequality (Scott, Gilbert, and Gelan 2007). Far from serving as a historical marker of identity, the rural/urban divide will continue to serve as a vital aspect of the $\mathrm{PoI}$ in the late twenty-first century. The parameters we chose for reviewing this literature largely ignored this question of the rural and urban and becomes a very important step in connecting questions of economic cooperation to larger questions about identity and political economy.

\section{Global Governance}

Critics of the United Nations Millennium Development Goals have argued that, while the outcomes are noble, they do not focus on authentically engaging the people for whom the goals are intended. Recent literature in development studies, particularly in China and India, have shown that the transition to the Sustainable Development Goals has revealed that one of the primary challenges to multilateral governance is the contextualization of those goals in both a local and national social context (David 2018; Xue, Weng, and Yu 2018). In many cases, more particularistic forms of governance move away from larger cooperative processes. We have come to know the most vocal of these "bunkered sentiments" in the form of economic nationalism (Shulman 2000; Ahlerup and Hansson 2011). Thus, in a world where RI catalyzes powerful political responses, what processes trigger such sentiments? More specifically, where do the technical aspects of RI intersect with the cultural phenomena that reject integrative gestures? 


\section{Effects of the COVID-19 Pandemic}

A further tension between RI and national identity can be seen in the recent COVID-19 crisis. While this is a situation where the usefulness of the development and application of joint international standards appears as a clear necessity given the rapid international spread of the virus, governance has been based on national interests, with governments and public opinions focused on responses that addressed their specific issues and needs, often at the expense of other states, with travel bans, governmental blocks on the exports of medically necessary supplies, and other similar measures.

This is creating a particularly worrisome situation, both within countries and in international trade. Some have suggested that the domestic psychology of economic policies, such as the risk of a "Keynesian supply shock" would trigger changes in aggregate demand larger than the shock itself (Guerrieri et al. 2020). The legal, political, and economic uncertainty is also predicted to determine a deglobalization of processes, taking the form of regionalization of global supply chains, recently strongly advocated by David Adler and Dan Breznitz in their article "Reshoring Supply Chain: A Practical Policy Agenda" (Adler and Breznitz, 2020), in which they propose a comprehensive agenda in order to ensure not only the political but also the economic benefits of such an approach. More recently, the deployment of vaccines has raised the attention on the issues related to vaccine nationalism (Kretchmer 2021).

\section{Parallel Economy, Informal Economy}

This is an issue that has not, so far, being investigated in terms of the PoI. Shortly after the 2008 economic crisis, economists presented the parallel economy (which includes informal economic activity, unaccounted economic output, the "shadow economy"/illicit activity) as an essential reactive element of economic downturn (Rowe 2012). The parallel economy, by design, is difficult to measure, but several attempts between 2013 and the present have measured the global parallel economy as between $21 \%$ and $56 \%$ of all economic activity. When you factor in various reasons why certain kinds of economic output are unaccounted for and underrepresented, an entire set of issues that relate to the PoI begin to present themselves. For example, the amount of informal labor produced in domestic spaces, including child care, have very strong cultural norms embedded in them, including gender norms that elevate themselves to regional status. The work of the poor or underserved and forms of informal barter are all tied to issues of identity ranging from questions of cultural authenticity to economic resistance to the state. As transnational spaces are produced, including those done across new 
economic formats of exchange, the systems that authenticate, regulate, and account for commercial activity will necessarily have to change. Forms of RI may manifest both directly and directly from trends within the parallel economy, which will necessarily contain an identity-formation dynamic.

\section{Section 4. Frameworks}

In Section 3, we provided an account on the main themes and integration issues through which the PoI is treated in relation to RI.

While the interaction emerges in various ways, what we notice is that there is still something missing in those approaches to help understand the profound interaction between RI and the PoI. The existing literature shows tensions and interaction between the two but does not provide analytical frameworks that help in understanding how they influence each other. It is our view that adopting such frameworks is necessary to fully understand processes that remain unexplained when the two concepts are treated as separate or only loosely related issues. Achieving this result would provide policymakers and scholars with a more complete set of tools to comprehend the effects of current RI mechanisms and identify the more adequate ones for specific situations.

In this section, which is the heart of our analysis, we provide basic elements for systemic and aesthetic approaches that would allow a fuller understanding of the interaction between RI and the PoI. These approaches serve as way for us to fulfill the more pedagogical objectives that prompted our review.

\section{A. Systemic Approaches}

\section{Imagined Communities}

Benedict Anderson's seminal Imagined Communities (2006) galvanized the idea that a nation is a complex arrangement of signs and symbols meant to generate a "broad horizontal kinship." As one of those conditions, Anderson suggests that every "imagined community" is limited, meaning that it cannot merely identify itself as is but must also define itself in relation to what it is not. This form of "Othering" is a mainstay of contemporary cultural theory, although it is largely underexpressed in studies of nationalism in the social sciences. Given the recent uprising of nationalism in the world, there is an opportunity to revisit this problem as a dialectical problem, and even more specifically, a value-based choice that is embodied in the goods, services, and people that travel across borders under changing RI policies. This kind of analysis can reconnect the problems of RI and economic nationalism with theories of identity, showing how trade processes transform the flow of goods 
and services into "sense objects" that reveal the values that ultimately are used to either accept or reject RI at the political level. Utilizing the imagined communities model addresses many of the issues related to symbolism and representation in the existing literature. By applying the four elements of an imagined community (imagined, limited, sovereign, and community), the current discursive frameworks can unfold even further in the context of a shared vocabulary regarding community and identity.

A great example of the imagined community model within RI exists in the $\mathrm{EU}$ and Brexit discussions, as it has been noted that the technical aspects of Brexit are revealing how the EU was not merely a call for economic cooperation; it was also a social experiment that used "Europeanness" and European identity to mitigate historical tensions within Europe (Dedman 1996; Cini and Borragán 2016).

A detailed study of how and why certain elements become identifiers of a shared identity is beyond the scope of this paper and should be the object of a separate study. It is, however, useful to mention some empirical examples that can be relevant in understanding the terms of the issue. This also takes into consideration that identity is in flux, and what is true today might not be so just a few years from now.

The assumption, when the project started in the 1950s with the creation of the three communities (European Coal and Steel Community, The European Economic Community, and Euratom), was that free trade and the creation of wealth would be sufficient to generate a European identity. However, after seventy years of unprecedented, generalized wealth and a period of peace unknown since the fall of the Western Roman Empire, Europeans are at their lowest level of trust and identification with the Union. Interestingly, a lot more has been done through the Erasmus program, which has favored friendships and relationships between students of different member states. Maybe mingling for an extended period helps create a common identity? While this remains to be evaluated, all four elements of imagined communities can be identified to some degree as follows:

- Imagined. A shared constitution. When member states tried to adopt a European constitution in the early 2000s, the project was soundly rejected in referenda in France and the Netherlands, while most of the same content passed in the Lisbon Treaty of 2007, which no longer appeared as a symbol.Limited. A common enemy. The process of European integration until the 1990s was also supported by the sense of cohesion of Western Europe against the Communist threat, and in fact nationalism surged after the collapse of the Communist bloc in Eastern 
Europe (Gerrits 2016). One can wonder whether the progressive crisis of the $\mathrm{EU}$ is also related to having lost a fundamental engine and symbol for its purpose. It is not a case that a further integration seems to be pushed by the French-German leadership, since the United States, during the Trump first mandate, has adopted a more adversarial position. Sovereign and community. Language. The EU is based on multilingualism, as was established immediately at the entering into force of the Treaty of Rome with Regulation no. 1/1958/CEE as a necessary principle to signify the equal relevance of all member states in line with what was initially largely a traditional multinational organization rather than an integration project. But has this been a good choice in the long term? Doesn't giving equal value to all national languages imply that the Union cannot be something more and different than the nation states rather than just a venue of cooperation of national identities? With the exiting of the UK from the Union and the fact that English is, in practice. used as the main working language in European institutions, one might want to consider making it the single official language of the EU in an effort to strengthen area sense of regional identity, possibly fulfilling the goal that the creation of Esperanto has not achieved.

A very interesting opportunity to evaluate the identity impact of EU initiatives and institutional developments will be provided by the implementation of the Recovery Fund, the massive 750 billion euro (almost 1 trillion USD) instrument approved to support the member states affected by the pandemic. What will be interesting to evaluate will be not only the technical viability of the instrument (after all, in recent years, anti-EU sentiment grew in Eastern Europe, notwithstanding large infusions of Structural Funds financing), but its symbolic and emotional impact. In other terms, will the new sense of solidarity at the base of the Fund strengthen the European sense of community so much bent since the Maastricht Treaty? Polls taken at the end of 2020 seem to show encouraging signs in this direction, with over $60 \%$ of the population across member states holding a favorable view of the EU and its handling of the pandemic response (Silver, Fagan, and Kent 2020). With a likely multiyear health crisis still ahead, this could represent a turning point in the development of an EU based on identity and not only technical instruments of RI.

\section{B. Social and Cultural Geography}

That constant attention to revising and supporting the openness of trade within the United States has elevated certain products to have a symbolic meaning 
that substantiates what they believe makes them belong to the world, which means it inheres in their beliefs as a moral right. Harley Davidson motorcycles must continue to be made to be both distinctly American and must themselves be able to fill in the space desired by Americans to produce Americana. The moment it is taxed or regulated in a way that obstructs that sense of American-ness validates a desire to break a contract with those that threaten that symbolic meaning. This is why Arjun Appadurai (1990) argues that all forms of political economy have a corresponding cultural economy. When RI contains technical aspects that are too removed from the ethical aspects that create "shared value," or "substance," agreements tend to break down. This is why Appadurai cites "cultural economy" as the vital corresponding tool in understanding the agenda of states. Without understanding the flow of objects, or the movement of things as contested objects, there is no way to understand globalization as part of a unified process of ethics and technical processes- the processes whereby people feel loss and nostalgia within their own cultural preferences and the process whereby people find a reason to sense a common good that deregulates the passage of people, places, and things. The field of cultural geography emanated from a consolidation of the study of politics and place, which itself turned to the process of mapping. This, added to the notion that ideas, sentiments, and habits can be mapped as much as much harder political borders created what we now commonly refer to as cultural geography (Cresswell 2004; Mitchell, 2008). Consequently, a framework for understanding RI would be served by using a cultural geographic framework. This both acknowledges the systemic features of RI while simultaneously attending to the ever-changing and evolving concept of "culture" and "identity."

\subsection{Aesthetic Approaches}

\subsection{A. Criticism and Objects}

Aesthetics tend to appeal to notions of sentimentality and belonging. When goods, services, people, and ideas cross boundaries, they play a role in expressing the geopolitical tensions wrought by RI. All objects (even the more abstract ones) are "sense objects," meaning they have aesthetic qualities that challenge us to make sense of the world. When RI policies change the mobility of objects across borders, economic choices also become aesthetic choices. Thus, it is important to understand the importance of aesthetics as a connector between RI and the PoI. 
To achieve this, we must spend some time exploring why aesthetics matter. Basically, aesthetics are "sense objects," and an aesthetic critique is a way of doing a focused interpretation of how these objects reveal our "sense of the world" by demonstrating how an object relates to a given social, economic, or political problem. A good way of doing this without fully immersing ourselves in the world of aesthetics and cultural criticism can be found in Gille Deleuze's important work, Difference and Repetition (1994). Deleuze famously used objects in Lewis Carroll's Alice in Wonderland to explore the cultural logic of economic progress in London during the latter part of the nineteenth century. The objects that Alice was encouraged to eat and drink were not merely random objects that she encountered in her fantastic journey. Deleuze proposed that they are narrative devices that connect Alice's ability to have an identity despite the chaotic landscape she must navigate in Wonderland. While Deleuze achieves this by critiquing novels, this type of critique can be applied to objects that move in the world through trade or physical exchange. A good or service that is subjected to a tariff, for example, is capable of revealing both the symbolic implications of imposing a tariff on that good and what that symbolic power says about the process of imposing a tariff itself. This gives us an entry point into framing and identifying how tariffs and quotas are used as foreign policy tools based on nationalism and how those processes segregate the rule of law from the emotional values that govern our choices and relations.

Aesthetic approaches are able to identify fractures and dichotomies within a complex discussion. For example, the following polarities are often present in discussions of RI:

Phronesis (ethical knowledge) versus Techne (productive knowledge)

Legitimacy versus

Discourse

Emotional belonging versus

Ethnic nationalism versus Rationalization (iron cage)

Democratically driven decisions versus Civic nationalism Political time (looking backward) versus Economic time (looking forward) These ingredients are all essential. One cannot exclusively focus on the political aspects without falling into the same rationalizing trap that it is focusing on. Therefore, performing aesthetic critiques helps determine how nationalism emanates from certain forms of RI. A person crossing the North Irish border is different from a bottle of Jameson crossing that same border because the specific technical aspects of a common market have different implications than those of free trade or a customs union. On the surface, 
this may seem intuitive until one has to investigate exactly how an object influences producers and consumers as it moves across any given border.

This was an important result of our cursory review of the literature. We noticed that the large majority of the literature we accessed did not address why certain objects or images ignite a sense of identity that responded directly to forms of RI. By introducing this approach, we suggest that one can help connect the tensions that occur in issues of RI by first understanding how people make sense of the world in the first place. Aesthetics become a principal way to understand identity, and by initially pointing out the dichotomies that occur when a physical landscape changes, one can understand the problem of RI as a problem of ethics and material culture. Part of the issue in RI is that the supranational or cross-national cooperation that occurs within those agreements is unable to replace the more visceral ways in which a nation ignites a sense of sentimentality and belonging. By considering aesthetics as part of that problem, one can more intimately connect the ways that identity emerges with the more technical aspects of economic cooperation.

\section{Final Remarks and Implications for Further Research}

Conclusively, in our work we have explored how RI, far from being a pure technical and economic issue, becomes a problem of the PoI when seen through the lens of the themes we have analyzed;it requires innovative methodological approaches in order to fully understand the working of the interaction between RI and the PoI.

Through our review, we have determined several key takeaways.

First, we found that the literature does not merely describe the institutionalization of outcomes intended to solve large-scale problems. Several studies highlight RI's nature as an experiment wherein citizens negotiate the viability of the kinship needed to cooperate at a multilateral level.

Second, those that experience RI are unequally invested and disinvested from that process, resulting in varieties of integration that necessarily produce the PoI, with the consequence that RI requires understanding of these identity reactions to be fully analyzed.

Third, critical approaches are necessary for delving more deeply into the richness of identity emerging from the previous point. These approaches allow us to articulate the process that is contained by the false positioning of dichotomies such as the ethnic versus the civic. While critiques of RI manifest as a loss of culture (an ethnic position), arguments to support RI are issued as outcomes that transcend cultural positions (a civic position). 
Fourth, to understand this dialectic positioning, we must accept that issues of economic integration directly impact the goods, services, people, and embodied ideas that mobilize culture and identity. When regional integration shifts, so too does the value of these objects, making them contested spaces of identity.

Fifth, the technical aspects of economic integration are often removed from the context wherein these objects become contested, and thus a framework is required to connect the technical functions of RI processes to better conceptualize the relationship between RI and identity structures such as nationalism. Use of these frameworks is what allows us to fill the gap between the current understanding of RI and full analysis of their implications and consequences.

Sixth, as RI evolves, an abundance of cultural forms manifest that contribute to the tension between region and nation.

Finally, we have considered the multifaced effects of the COVID-19 pandemic, which has at the same time stressed the need for planetary belonging and determined nationalist reflexes in many government responses.

The outcome of these reflections is that, while the literature reaches far into the details of nationalism and identity, there is a large discrepancy in the use of the PoI as a way of addressing all relevant RI issues. This is likely the result of structural paradigms within the disciplines that study each of these subjects. For many, RI is an economic or commercial term that does not yet have currency within fields that are more strongly situated in the humanities.

Our conclusion is, thus, that it is necessary to break with these structural paradigms to develop effective strategies to address RI, fully comprehend all its implications, and be able to better develop strategies and policy proposals. This will be done by ensuring that RI and the PoI are more commonly associated with one another, particularly at a time when every economic choice appears as an existential crisis for one group or another.

This reinforces why the problems of political and cultural economy are such nuanced concepts and why the suggested frameworks may advance our understanding of these problems. We therefore suggest the urgency of further developing use of the frameworks we have proposed and look forward to furthering development of the academic investigation in this direction, in order to provide a more complete view for policy developments in RI.

Our review was neither intended to be comprehensive nor was it intended to redefine our understanding of the essential vocabulary. It was intended directly to replicate the production of "textbook" and technical knowledge to 
issues and sentiments that are embedded in students' needs. We believe this approach helps one work through the very difficult task of putting economic terminology more comprehensively in the hands of students who are wrestling with both the esoteric and popular forces that shape the political economy and the prospects for economic cooperation.

\section{References}

Adler, David, and Dan Breznitz. 2020. "Reshoring Supply Chains: A Practical Policy Agenda." American Affairs 4(2): 6-17.

Ahlerup, Pelle, and Gustav Hansson. 2011. "Nationalism and Government Effectiveness."Journal of Comparative Economics 39(3): 431-51.

Anderson, Benedict. 2006. Imagined Communities: Reflections on the Origin and Spread of Nationalism. London: Verso Books.

Appadurai, Arjun. 1990. "Disjuncture and Difference in the Global Cultural Economy." Theory, Culture \& Society 7(2-3): 295-310.

Arendt, Hannah. 1973. The Origins of Totalitarianism.. New York: Harcourt Brace Jovanovich..

Bhalla, Ajit S., and Praveen Bhalla. (2016). Regional Blocs: Building Blocks or Stumbling Blocks? London: Palgrave Macmillan.

Bowen, John Richard. 1996. "The Myth of Global Ethnic Conflict.” Journal of Democracy 7(4): 3-14.

Caporaso, James A., and John T. S. Keeler. 1993. "The European Community and Regional Integration Theory.” http://aei.pitt.edu/7252/1/002711_1.PDF.

Carranza, Mario Esteban. 2017. South American Free Trade Area or Free Trade Area of the Americas?: Open Regionalism and the Future of Regional Economic Integration in South America: Open Regionalism and the Future of Regional Economic Integration in South America. [London]: Routledge.

Cini, Michelle, and Nieves Pérez-Solórzano Borragán, eds. 2016. European Union Politics. 5th ed. Oxford: Oxford University Press.

Connor, Walker. 1978. “A Nation Is a Nation, Is a State, Is an Ethnic Group Is a...." Ethnic and Racial Studies 1(4): 377-400.

Côté-Boucher, Karine. 2013. "The Micro-Politics of Border Control: Internal Struggles at Canadian Customs.” PhD diss., York University, http://hdl.handle.net/10315/27585.

Cresswell, Tim. 2004. Place: A Short Introduction. Malden, MA: Blackwell.

David, M. 2018. "Sustainable Development Goals (SDGs): Challenges for India." Indian Journal of Public Health Research \& Development 9(3).

Dedman, Martin J. 1996. The Origins and Development of the European Union 1945-1995: A History of European Integration. London: Routledge.

Deleuze, Gilles. 1994. Difference and Repetition. New York: Columbia University Press.

DeSoucey, Michaela. 2010. "Gastronationalism: Food Traditions and Authenticity Politics in the European Union.” American Sociological Review 75(3): 432-55. 


\section{Journal of Nationalism, Memory \& Language Politics 15(1)}

Galperin, Hernan. 1999. "Cultural Industries Policy in Regional Trade Agreements: The Cases of NAFTA, the European Union and MERCOSUR. Media, Culture \& Society 21(5): $627-48$.

Gálvez, Alyshia. 2018. Eating NAFTA: Trade, Food Policies, and the Destruction of Mexico. Oakland, CA: University of California Press.

Garcia, D. Linda. 2005. “Cooperative Networks and the Rural-Urban Divide.” In Digital Formations: IT and New Architectures in the Global Realm, edited by Saskia Sassen and Robert Latham, 117-45. Princeton, NJ: Princeton University Press.

Gouveau, Raul, and Manuel Montoya. 2014. "Mercosur after Chavez." Thunderbird International Business Review 56(6): 563-75.

Greenfeld, Liah. 2018. “The World Nationalism Made." American Affairs 2(4): 145-59.

Gubrium, Jaber F., and James A. Holstein. 2001. Institutional Selves: Troubled Identities in a Postmodern World. Oxford: Oxford University Press.

Guerrieri, Veronica, Guido Lorenzoni, Ludwig Straub, and Iván Werning. 2020. Macroeconomic Implications of COVID-19: Can Negative Supply Shocks Cause Demand Shortages? Working Paper Series, no. w26918). Cambridge, MA: National Bureau of Economic Research.

Helleiner, Eric, and Andreas Pickel. eds. 2005. Economic Nationalism in a Globalizing World. Ithaca, NY: Cornell University Press.

Ignatieff, Michael. 1994. Blood and belonging: Journeys into the new nationalism. Macmillan.

Jones, Erik. 2019. Do Central Bankers Dream of Political Union? From Epistemic Community to Common Identity." Comparative European Politics 17(4): 530-47.

Kaelberer, Matthias. 2004. "The Euro and European Identity: Symbols, Power and the Politics of European Monetary Union.” Review of International Studies 30(2): 161-78.

Kahler, Miles. 2013. "Economic Crisis and Global Governance: The Stability of a Globalized World. Procedia-Social and Behavioral Sciences 77: 55-64.

Kar, Arpan Kumar, Vigneswara Ilavarasan, M. P. Gupta, Marijn Janssen, and Ravi Kothari. 2019. "Moving Beyond Smart Cities: Digital Nations for Social Innovation \& Sustainability. Information Systems Frontiers 21(3): 495-501.

Katsanidou, Alexia, and Simon Otjes. 2016. "How the European Debt Crisis Reshaped National Political Space: The Case of Greece.” European Union Politics 17(2): 262-84.

Keith, Michael, and Steve Pile, eds. 2004. Place and the Politics of Identity. London: Routledge.

Keohane, Robert. O. 2003. "Global Governance and Democratic Accountability." In Taming Globalization: Frontiers of Governance, edited by David Held and Mathias Koenig-Archibugi, 130-56. Cambridge, UK: Polity Press.

Kobrin, Stephen J. 1995. "Regional Integration in a Globally Networked Economy." Transnational Corporations 4: 15-33.

Kretchmer, Harry. 2021. "Vaccine Nationalism—and How It Could Affect Us All.” World Economic Forum 6: 27-39. 
Lähdesmäki, Tulli, and Katja Mäkinen. 2019. “The 'European Significance' of Heritage.” In Politics of Scale: New Directions in Critical Heritage Studies, edited by Tuuli Lähdesmaki, Suzie Thomas, and Yujie Zhu, 36: 73-75 New York: Berghhan Books.

Loftsdóttir, Kristin. 2009. "Invisible Colour: Landscapes of Whiteness and Racial Identity in International Development." Anthropology Today 25(5), 4-7.

Mansfield, Edward D., and Helen V. Milner. 2012. Votes, Vetoes, and the Political Economy of International Trade Agreements. Princeton, NJ: Princeton University Press.

Menon, Jayant. 2007. "Building Blocks or Stumbling Blocks? The GMS and AFTA in Asia." ASEAN Economic Bulletin 24(2): 254-66.

Mitchell, Don. 2008. Cultural Geography: A Critical Introduction. Malden, MA: Blackwell.

Mycock, Andrew. 2012. "SNP, Identity and Citizenship: Re-imagining State and Nation." National Identities 14(1): 53-69.

Payne, Anthony. 2008. "The G8 in a Changing Global Economic Order." International Affairs 84(3): 519-33.

Reus-Smit, Christian. 1999. The Moral Purpose of the State: Culture, Social Identity, and Institutional Rationality in International Relations. Princeton, NJ: Princeton University Press.

Robinson, John B., and Deborah Herbert. 2001. "Integrating Climate Change and Sustainable Development." International Journal of Global Environmental Issues 1(2): 130-49.

Rowe, Jonathan. 2012. "The Parallel Economy of the Commons." In State of the World 2008: Ideas and Opportunities for Sustainable Economies, 166-78). Hoboken, NJ: Taylor \& Francis.

Rwengabo, Sabastiano. 2015. "From Migration Regime to Regional Citizenry: Migration and Identity Implications of the East African Common Market." Eastern Africa Social Science Research Review 31(2): 35-61.

Scholte, Jan Aart. 2004. "Civil Society and Democratically Accountable Global Governance. Government and Opposition 39(2): 211-33.

Scott, Alister, Alana Gilbert, and Ayele Gelan. 2007. The Urban-Rural Divide: Myth or Reality? Aberdeen: Macaulay Institute.

Shulman, Stephen. 2000. "Nationalist Sources of International Economic Integration.” International Studies Quarterly 44(3): 365-90.

Silver, Laura, Moira Fagan, and Nicholas Kent. 2020. Majorities in the European Union Have Favorable Views of the Block, Pew Research Center, November 17, https://www.pewresearch.org/global/2020/11/17/majorities-in-the-european-union-have-favorable-views-ofthe-bloc/.

Simmel, Georg, and Thomas Burton Bottomore. 2004. The Philosophy of Money. 3rd enl. ed. London: Routledge.

Spruyt, Hendrik. 1994. "Institutional Selection in International Relations: State Anarchy As Order." International Organization 48(4): 527-57.

UNCTAD. 2017. “Energizing Rural Development.” Policy Brief, no. 54. https:/unctad.org/ en/pages/PublicationWebflyer.aspx?publicationid=1909.

Williams, Raymond, 1977. Marxism and Literature. Oxford Paperbacks 392. Oxford: Oxford University Press. 
Journal of Nationalism, Memory \& Language Politics 15(1)

Xue, Lan, Lingfei Weng, and Hanzhi Yu. 2018. "Addressing Policy Challenges in Implementing Sustainable Development Goals through an Adaptive Governance Approach: A View from Transitional China. Sustainable Development 26(2): 150-58.

Zahariadis, Nikolaos. 2010. "Greece's Debt Crisis: A National Tragedy of European Proportions.” Mediterranean Quarterly 21(4):38-54. 